\title{
The Effect of a Short Period of Supplementation with Glutamine Dipeptide on the Cognitive Responses after a Resistance Training Session of Women with HIV/AIDS: A Randomized Double-Blind Placebo-Controlled Crossover Study
}

\author{
Dayane Cristina de Souza $\mathbb{D}^{1},{ }^{1}$ Junior Cesar da Silva, ${ }^{1}$ Felipe de Oliveira Matos ${ }^{\mathbb{D}},{ }^{1}$ \\ Alexandre Hideki Okano $\mathbb{D}^{2},{ }^{2}$ Roberto Barbosa Bazotte, ${ }^{3}$ and Ademar Avelar ${ }^{1}{ }^{1}$ \\ ${ }^{1}$ Department of Physical Education, State University of Maringá, Maringá, PR, Brazil \\ ${ }^{2}$ Center of Mathematics, Computation and Cognition, Universidade Federal do ABC, São Bernardo do Campo, SP, Brazil \\ ${ }^{3}$ Department of Pharmacology and Therapeutics, State University of Maringá, Maringá, PR, Brazil
}

Correspondence should be addressed to Ademar Avelar; ademaravelar@yahoo.com.br

Received 25 October 2017; Accepted 25 February 2018; Published 3 April 2018

Academic Editor: Lucia Lopalco

Copyright (c) 2018 Dayane Cristina de Souza et al. This is an open access article distributed under the Creative Commons Attribution License, which permits unrestricted use, distribution, and reproduction in any medium, provided the original work is properly cited.

The aim of the present study was to investigate the effect of a short period of supplementation with glutamine dipeptide (GDP) on the acute responses to resistance training on the executive functions of people with HIV/AIDS. The sample consisted of $10 \mathrm{HIV}+$ women $(45.00 \pm 12.77$ years old; $65.71 \pm 12.04 \mathrm{~kg} ; 1.54 \pm 0.05 \mathrm{~m})$ who were submitted to a randomized double-blind crossover procedure according to two experimental conditions: orally supplemented with $20 \mathrm{~g} /$ day of GDP or with maltodextrin for seven days. On the seventh day of supplementation all participants did cognitive function tests before and immediately after a resistance training session. Seven days of washout were adopted between conditions. Stroop and N-back tests were used to evaluate the executive functions. The training reduced the response time of each card in isolation and the latency time among them. GDP supplementation increased the magnitude of this effect, thus, reducing the latency time from the first to the last card in the Stroop test by almost $50 \%(P<0.01)$. Considering the $N$-back test, there were no significant differences. It is suggested that GDP supplementation may increase the magnitude of the effect of an acute resistance training session in cognitive functions, particularly in the inhibitory control of people with HIV/AIDS. This trial is registered with NCT03236532.

\section{Introduction}

The immune system is not the only one to be compromised by the Human Immunodeficiency Virus (HIV) but it is possible to find such a virus in the Central Nervous System (CNS) [1]. It has been reported that the virus enters the CNS during the primary infection phase through a mechanism referred to as the "Trojan Horse," in which the virus uses T-CD4+ and T-CD8+ lymphocytes, monocytes, and/or macrophages in order to cross the blood-brain barrier. This allows a virus replication in the CNS [2-4] and may trigger cognitive deficits of different intensities, with the dementia associated with HIV being the most serious of them [5].
The main regions of the brain affected by the virus are cortical and subcortical structures, such as frontal lobes [6] responsible for executive functions. These functions are understood as a set of cognitive abilities that control specific abilities, referring to the capacity of adaptive response to everyday situations, being the basis of many emotional and social competences [7].

The executive functions are comprised basically of three components, being (1) the working or operational memory, which is the capacity to integrate sensorial information in past experiences; (2) the preparatory set, which refers to the ability to organize and coordinate goal-directed behavior; (3) inhibitory control, which plays a role in the temporal 
organization of behavior and aims to suppress internal or external influences that may interfere with the sequence of ongoing action [7]. The impairment of these functions may significantly reflect the functioning of daily activities of HIVinfected persons [8]. Some studies also address the vulnerability of women in developing these neuropsychological impairments associated with HIV $[9,10]$. Therefore, strategies to address impairments related to cognitive deficits in women living with HIV are needed.

Physical exercise programs and nutritional modulation have been investigated in isolation [11-13] and/or in combination [14] lately, in order to reduce or even prevent the progression of damage caused by different types of dementia in different populations. Specifically, the model of resistance training has been shown to be able to change the path of cognitive and motor decline, in addition to improving cerebral perfusion and executive functions [15-19], even after a single training session [20-22]. However, there are no similar studies on people with HIV/AIDS, although some studies show an association between active lifestyle and an improved brain function/integrity $[23,24]$. In addition, practicing physical exercise may reduce the probability of neurocognitive impairment of people with HIV/AIDS by up to 50\% [25]. Only one study investigated the effect of physical exercise intervention on the cognitive function, as their primary outcomes, and did not find significant results after 16 weeks of aerobic exercise [26] instigating the need for new research in this area with different exercise models on participants with HIV.

Regarding the nutritional aspects, the investigations that search to understand the mechanisms in the CNS that lead to the development of some dementia are highlighted. In this context, some authors have investigated the hypothesis of glutamine involvement in brain functions, making the key role of this amino acid in the CNS metabolism clear [27, 28].

Considering the HIV+ population, it has been shown that the serum glutamine concentration may reach a reduction of about $40 \%-50 \%$ due to the accelerated metabolism of the immune system cells $[29,30]$. Therefore, glutamine supplementation may propitiate the increase of its concentration in the blood, enabling its action as a source of energy for the immune system. Furthermore, an increased availability of glutamine may favor the endogenous synthesis of glutathione [29], an important antioxidant that protects the cell, which has also been related to the treatment of cognitive disorders.

Based on the facts described above, this study aims at investigating the effect of a resistance training session associated with a short period of glutamine dipeptide (GDP) supplementation on the cognitive responses of women with HIV/AIDS, in view of the hypothesis that physical exercises may improve the executive functions in this population and that the GDP supplementation is able to increase this effect.

\section{Methods}

2.1. Participants. Initially 56 subjects were interviewed for eligibility in this study; of these 16 did not meet the inclusion criteria and 26 refused to participate. Fourteen women diagnosed with HIV+ participated in the randomization described in Figure 1.
As inclusion criteria, they should be over 18 years old; they should have regularly been using the Antiretroviral Therapy for more than six months; they should have a stabilized clinical picture and viral load; they should not have participated in physical training programs during the preceding six months; they should not show acute or chronic inflammations that could affect the practice of physical exercise; they should not have psychiatric disorders; and they should not be pregnant.

The individuals who met the inclusion criteria received clinical evaluation by the infectious physician responsible for the treatment based on the history of each patient, the laboratory tests, and the clinical picture.

The study was approved by the Standing Committee on Ethical Research with Humans of the State University of Maringá, PR, Brazil. The volunteers signed the Free Informed Consent Form, after being informed about the study proposal and the procedures they would be submitted to.

During the study period, four participants were not able to attend all the evaluations and were excluded from the final analysis. Therefore, 10 women participated in all the procedures and were part of the final sample of the study.

2.2. Experimental Design. As described in Figure 2, the study had a total duration of five weeks divided into four phases. The first phase lasted two weeks and was characterized by familiarization with the exercises that would be performed in the second and fourth phases. This protocol consisted of four sessions of exercises, every 48 hours, which presented individuals to the same procedures that would be done in phases two and four. Four familiarization sessions were chosen, one of which aimed to learn the exercises without the insertion of loads. Then the participants could rest a week before starting the second phase.

In the second phase the participants were randomly separated in a double-blind manner to ingest GDP (Condition 1) or maltodextrin as a placebo (Condition 2) for seven days. On the seventh and last day of supplementation, they were submitted to the resistance training session. Before and immediately after the exercise session, cognitive tests were applied. The third phase consists of a rest period of one week. In the fourth phase the procedures performed in the second phase were repeated. However, the group that received GDP began to receive maltodextrin, and the group that received maltodextrin began to receive GDP, thus adopting a randomized double-blind crossover project.

2.3. Evaluation of the Cognitive Status. Considering the general evaluation of possible cognitive impairments, the Mini Mental State Examination (MMSE) was used, which provides information on different cognitive parameters, considering the level of education of the individual evaluated [31]. In order to assess the indicatives of HIV-associated dementia the International HIV Dementia Scale was applied [32].

2.4. Executive Functions. The Victoria Stroop color-word test was used to evaluate the executive functions [33], which consists of 72 stimuli, distributed in three cards with 24 items each (A, B, and C). The subject must verbalize the name of the colors with which the stimuli of each card were printed 


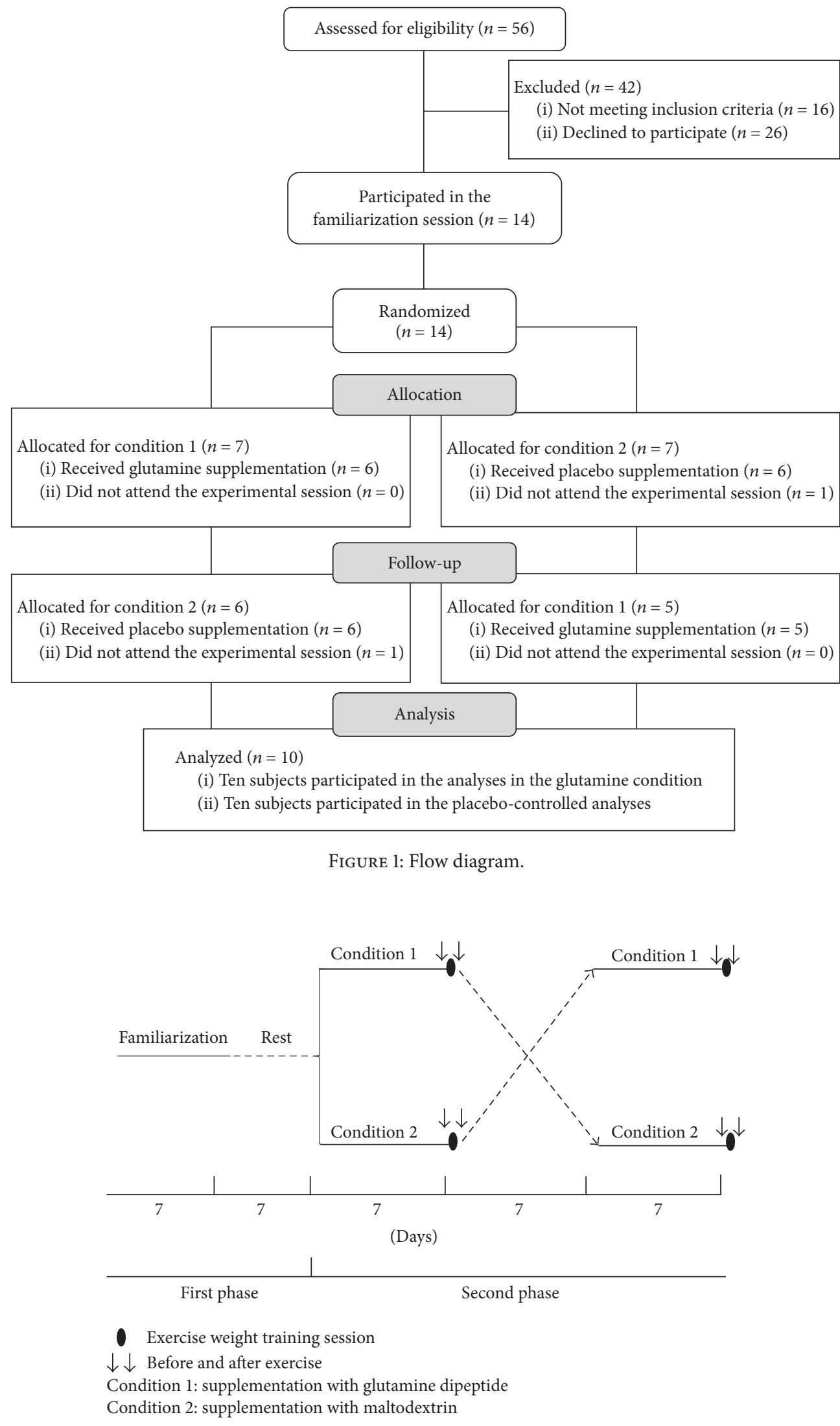

FIGURE 2: Scheme of the experimental design. 
as quickly as possible; the time spent to read each of the cards separately was registered. The latency time, which is determined by the difference between the time spent with the responses to the three cards, was used to evaluate selective attention and inhibitory control.

The $N$-back test was used to evaluate the operational memory [34]. Visual stimuli were used in this study, which were represented by colors, divided into three levels $(N 1, N 2$, and N3) with 150 stimuli each. The score of each participant was obtained from the percentage values of the hits recorded in the three levels in a computerized version of the test.

2.5. The Resistance Training Protocol. The exercises were based on the Guideline for the prescription of exercise to be given to people with HIV/AIDS [35]. The training session consisted of seven exercises with weights (chest press, leg press $45^{\circ}$, lat pulldown machine, knee extension, triceps pulley, knee curl, and Scott biceps curl machine) involving different muscle groups with three series per exercise.

The recovery interval adopted was of 90 seconds between the series and 120 seconds between exercises. The number of repetitions used in each one of these series was of 8-12 repetitions by applying the method of fixed loads. The loads were compatible with the number of repetitions stipulated for each exercise. The load determination occurred during familiarization sessions.

The OMNI Resistance Exercise Scale (OMNI-RES) of effort subjective perception was used to determine and control the loads of each exercise. The loads used during the experimental sessions corresponded to the intensity equivalent to the interval from five to seven (5-7) of the OMNI-RES scale.

In order to achieve such a purpose, prior to the beginning of familiarization with the exercises, the OMNI-RES scale anchoring was performed. This procedure consists of placing the patient in the smallest and highest possible load in each exercise so that he/she can differentiate a smaller and a greater subjective perception of effort.

2.6. Supplementation Protocol. The participants were randomly double-blinded indicated to receive either GDP ( $20 \mathrm{~g} /$ day) or maltodextrin $(20 \mathrm{~g} /$ day) according to the literature [29]. The substances were packed in sachets containing GDP or maltodextrin (placebo). The packages were identical and the substances used had a similar color and texture. Participants were instructed to dilute GDP or maltodextrin in $300 \mathrm{ml}$ of water and ingest it after lunch. In case of forgetfulness, they were suggested to ingest it soon after dinner. All participants were instructed to maintain their routine eating habits throughout the duration of the study.

2.7. Statistical Analysis. The descriptive statistics were used to characterize the sample. Shapiro-Wilk test was used for data distribution analysis. For the variables that showed a parametric distribution, the independent $t$-test was used in order to compare the preexercise values. For the variables that did not show a parametric distribution, Mann-Whitney $U$ test was used with the same purpose. Mauchly's sphericity test was used to verify the sphericity of the data. Considering the
TABLE 1: Characterization of the participants of this study $(n=10)$.

\begin{tabular}{lcc}
\hline Variable & Mean & Standard deviation \\
\hline Age (years) & 45.0 & \pm 12.8 \\
BMI $\left(\mathrm{kg} / \mathrm{m}^{2}\right)$ & 27.4 & \pm 4.0 \\
CD4 $\left(\mathrm{mm}^{3}\right)$ & 369.7 & \pm 202.0 \\
CD8 $\left(\mathrm{mm}^{3}\right)$ & 802.8 & \pm 308.7 \\
CD4/CD8 & 0.4 & \pm 0.3 \\
ART time (years) & 6.1 & \pm 5.6 \\
MMSE (score) & 27.5 & \pm 1.0 \\
IHDS (score) & 11.6 & \pm 0.5 \\
\hline
\end{tabular}

BMI $=$ Body Mass Index; ART $=$ Antiretroviral Therapy; MMSE $=$ Mini Mental State Examination; IHDS = International HIV Dementia Scale .

variables in which the sphericity was violated, the analyses were adjusted by using the Greenhouse-Geisser correction. The two-way ANOVA (time $\times$ supplement) for repeated measurements was used for intra- and intercondition comparisons. Bonferroni post hoc test was used when a significant $F$ ratio was identified either for an isolated effect of the factors analyzed or for the interaction among them. All data were treated with the Statistics software, version 7.0. The significance level of $P<0.05$ was adopted for all analyses.

\section{Results}

The data related to the characterization of the participants showed in Table 1 include the information obtained in the questionnaires applied to detect the presence of cognitive deficit. The results show that, in spite of being infected by the virus, the participants do not have cognitive impairments of the domains evaluated by the International HIV Dementia Scale and the MMSE.

The results obtained by using Stroop test are shown in Table 2. The data are presented by means of the preand postexercise time for each of the cards $(\mathrm{A}, \mathrm{B}$, and $\mathrm{C})$ individually.

Stroop test is considered a neuropsychological test sensitive to impairment in the executive functions, more specifically attention and inhibition. The results showed an isolated effect of the time factor (training session) considering the independent analysis of each card (A, B, and C) with a significant reduction in the comparisons between before and after acute resistance training sessions, in addition to a reduction in the latency time from card B to card C $(P<0.01)$ and from card $\mathrm{A}$ to card $\mathrm{C}(P<0.01)$.

The interaction from time versus supplementation in the latency time from the first to the last card showed that the participants, after being supplemented for seven days with GDP, presented a significant decrease $(P<0.01)$ in the response time between the cards, when compared to the preand postexercise evaluation.

For the central executive component of the operational memory, measured by visual stimuli and using the $N$-back test, no effect was found (GDP: before $34.7 \pm 19.0$ and after $43.3 \pm 16.4$; placebo: before $39.8 \pm 18.7$ and after $39.2 \pm 16.4)$, both in an isolated way $(P$ time $=0.29 ; P$ supplement $=0.95)$ and with the interaction between them $(P=0.23)$. 
TABLE 2: Stroop test results when comparing maltodextrin (placebo) versus glutamine dipeptide (GDP) supplementation before and after an acute resistance training session $(n=10)$. Values expressed as mean \pm and standard deviation.

\begin{tabular}{|c|c|c|c|c|c|}
\hline & Placebo & GDP & Effects & $F$ & $P$ \\
\hline \multicolumn{3}{|c|}{$T$ _latency: A-B (seconds) } & \multicolumn{3}{|l|}{ ANOVA } \\
\hline Pre & $1.6 \pm 3.7$ & $2.3 \pm 3.2$ & Supplement & 0.01 & 0.93 \\
\hline \multirow[t]{2}{*}{ Post } & $2.6 \pm 2.0$ & $2.1 \pm 2.1$ & Time & 0.34 & 0.57 \\
\hline & & & Supplement $\times$ time & 0.97 & 0.34 \\
\hline \multicolumn{3}{|c|}{$T$ latency: B-C (seconds) } & \multicolumn{3}{|l|}{ ANOVA } \\
\hline Pre & $7.0 \pm 7.1$ & $7.9 \pm 7.0$ & Supplement & 0.05 & 0.83 \\
\hline \multirow[t]{2}{*}{ Post } & $5.2 \pm 4.7$ & $3.3 \pm 3.1$ & Time & 11.60 & $<0.01$ \\
\hline & & & Supplement $\times$ time & 0.97 & 0.34 \\
\hline \multicolumn{2}{|c|}{ T latency: A-C (seconds) } & & \multicolumn{3}{|l|}{ ANOVA } \\
\hline Pre & $8.6 \pm 7.5$ & $10.2 \pm 6.2$ & Supplement & 0.03 & 0.87 \\
\hline \multirow[t]{2}{*}{ Post } & $7.7 \pm 5.3$ & $5.4 \pm 3.6^{*}$ & Time & 13.44 & $<0.01$ \\
\hline & & & Supplement $\times$ time & 6.28 & 0.02 \\
\hline \multicolumn{2}{|c|}{ Card: A (seconds) } & & \multicolumn{3}{|l|}{ ANOVA } \\
\hline Pre & $15.2 \pm 3.6$ & $15.2 \pm 1.9$ & Supplement & 0.49 & 0.49 \\
\hline \multirow[t]{2}{*}{ Post } & $13.2 \pm 2.0$ & $14.5 \pm 1.8$ & Time & 8.02 & 0.01 \\
\hline & & & Supplement $\times$ time & 1.41 & 0.25 \\
\hline \multicolumn{2}{|c|}{ Card: B (seconds) } & & \multicolumn{3}{|l|}{ ANOVA } \\
\hline Pre & $16.8 \pm 3.8$ & $17.6 \pm 3.7$ & Supplement & 0.29 & 0.60 \\
\hline \multirow[t]{2}{*}{ Post } & $15.6 \pm 3.3$ & $16.5 \pm 2.8$ & Time & 7.18 & 0.01 \\
\hline & & & Supplement $\times$ time & 0.01 & 0.98 \\
\hline \multicolumn{3}{|c|}{ Card: C (seconds) } & \multicolumn{3}{|l|}{ ANOVA } \\
\hline Pre & $23.8 \pm 9.4$ & $25.5 \pm 7.5$ & Supplement & 0.01 & 0.93 \\
\hline \multirow[t]{2}{*}{ Post } & $20.9 \pm 6.4$ & $19.8 \pm 4.9$ & Time & 25.59 & $<0.01$ \\
\hline & & & Supplement $\times$ time & 2.66 & 0.12 \\
\hline
\end{tabular}

${ }^{*} P<0,01$ versus Pre; $T$ _latency $=$ Time of Latency.

\section{Discussion}

The findings of the present study indicate that resistance training can improve the cognitive responses of people with HIV/AIDS, thus intervening both in selective attention and in inhibitory control, which refer to one of the three central components of executive functions [7], that is, the capacity of focusing attention on specific stimuli and disregarding irrelevant stimuli [36].

The favorable effect of resistance training in the sense of reducing the cognitive and motor decline, besides improving cerebral perfusion and executive functions $[15,16,19]$, has been reported in previous studies [20-22]. However, these results were obtained from people of different ages [20$22,37-41]$ and pathologies $[37,42,43]$ in addition to the absence of studies that evaluate the effect of the training on the cognition of HIV-infected individuals.

It is worth emphasizing that HIV may lead to important changes in cognition [44] and, therefore, it is possible that it also directly influences the responses to exercise. Thus, the results of the present study may be a reference base when dealing with the effect of this training model on the cognition of people with HIV/AIDS.

In the literature, the neuroprotective effect of physical exercise considering the decline of cognitive functions and the risk of dementia, such as Alzheimer's disease, has been pointed out $[42,43]$. Therefore, the results obtained suggest that, as in the elderly population, resistance training, even acutely, may also positively influence cognitive aspects in the $\mathrm{HIV}+$ population.

The cognitive improvement by doing physical exercise would be related to the elevated release of neurotransmitters (norepinephrine, serotonin, and endorphin) and their precursors [45] as well as an increased blood flow in different areas of the brain, representing a higher supply of oxygen and nutrients and, consequently, a higher energy supply [46].

The hypothesis of this study that GDP supplementation could increase the effect of the exercise on the executive functions was confirmed in the interaction analysis of the time versus supplement and in the latency time from the first card (A) to the last one (C) by using Stroop test. The participants, when supplemented with GDP, showed a mean reduction of $47.1 \%$ in the response time among the cards, whereas under the placebo condition they showed a mean reduction of only $10.5 \%$.

Considering that people with HIV/AIDS have a reduced serum concentration of glutamine [29, 30, 47, 48], it is possible that the main performance of this amino acid in the cognitive aspects is related to the increase of neurotransmitter amino acid synthesis, although it is not clear if this occurs through the excitatory or inhibitory pathway, thus requiring further studies to confirm this premise. 
Another possibility is related to the role of glutamine as a source of energy for the brain [44], in addition to the increase of the endogenous synthesis of glutathione [29]. People who live with HIV have reduced the glutathione levels, which is similar to the impacts caused in the CNS through some processes, that is, aging and different diseases, such as Alzheimer's and Parkinson's [29, 49]. Glutathione is an antioxidant used in the combat of cognitive disorders, since it acts as an important neuromodulator in the CNS $[47,50]$.

Besides being a precursor of glutathione, the glutamine plays the same role in relation to glutamate, the main excitatory CNS neurotransmitter, aspartate, and gamma-aminobutyric acid (GABA), the main inhibitory neurotransmitter [48].

Considering that high levels of glutamate can be toxic to the CNS [51], the findings by Borges-Santos et al. [29] show a positive response, which evidences that glutamine supplementation is able to significantly increase serum concentrations of glutathione in people with HIV, without significantly increasing the glutamate concentrations.

However, in order to confirm these possible associations, further studies should be carried out with more accurate methods of evaluation and able to determine if the GDP supplementation may increase the concentrations of glutamine and its precursors in the CNS.

Despite the evidence of the glutamine role in the CNS, its involvement in cognitive responses remains unclear. This is because some of the studies that investigated the possible effects of nutritional modulation on cognitive responses used vitamin and/or lipid supplements and the results do not make it clear if there really is any ergogenic effect.

When analyzing the nutrition and cognition relation, it is seen that the resistance training associated with protein supplementation would improve the speed of information processing in the elderly. The resistance training itself has improved attention and working memory. The few studies that evaluated the impact of glutamine supplementation on cognitive responses found improvement in children's learning index [13] and in the reaction time in endurance athletes [52]. However, in the present study no difference was found in the comparison of prevalues (glutamine versus placebo), which shows that one week of glutamine supplementation alone did not result in cognitive improvement.

In tasks as the $N$-back, the content of the operational memory needs to be constantly manipulated, since the target stimulus is updated to each item shown [53]. In this study, no significant change was found in the assessment of operational memory, assessed by the $N$-back test.

Knowing that the operational memory is a system of limited capacity, it is common that the individuals evaluated have a poor performance as the test level increases [54]. It was expected that, after the resistance training session and/or with the GDP supplementation, this performance would improve; however this did not happen, both in the analysis of the isolated factors and in the analysis of the interaction between these two factors.

It is important to highlight that the supplementation time and the sample size may have influenced the results of the present investigation and may have eased the possible impact of the association between resistance training and GDP supplementation considering the parameters evaluated. Another relevant aspect is the lack of a more sensitive evaluation method to detect possible changes in a short period of time.

Despite these limitations, the results obtained are promising, in particular the demonstration of the positive impact of physical exercise on the cognitive responses of people with HIV/AIDS. In addition, the results raise the possibility of an additional benefit from GDP supplementation for a short period of time. Therefore, further studies should be carried out with the aim of evaluating the chronic impact of the exercises and/or GDP supplementation on the cognitive responses of people with HIV/AIDS.

\section{Conclusion}

Acute resistance training was sufficient to improve in the executive function, specifically in the inhibitory control in women with HIV/AIDS. This response was even more expressive when associated with the GDP supplementation, but there were no significant changes in the operational memory.

\section{Conflicts of Interest}

The authors hereby declare that there are no conflicts of interest.

\section{Acknowledgments}

The authors acknowledge both, the Center of Excellence in Physical Activity (CEAF) for the use of the academy and the Center of Testing and Counseling (CTA) to the HIV/AIDS Patient (Maringá, PR, Brazil) for enabling the contact with the participants of this study. The authors "Dayane Cristina de Souza" and "Junior Cesar da Silva" received individual funding from the Coordination for the Improvement of Higher Education Personnel (CAPES). This research was financed by the National Council of Scientific and Technological Development (CNPq), Brazil.

\section{References}

[1] V. Tozzi, P. Balestra, R. Bellagamba et al., "Persistence of neuropsychologic deficits despite long-term highly active antiretroviral therapy in patients with HIV-related neurocognitive impairment: prevalence and risk factors," Journal of Acquired Immune Deficiency Syndromes, vol. 45, no. 2, pp. 174-182, 2007.

[2] M. Ghafouri, S. Amini, K. Khalili, and B. E. Sawaya, "HIV-1 associated dementia: symptoms and causes," Retrovirology, vol. 3, no. 1, article 28, 2006.

[3] J. Schouten, P. Cinque, M. Gisslen, P. Reiss, and P. Portegies, "HIV-1 infection and cognitive impairment in the cART era: a review," AIDS, vol. 25, no. 5, pp. 561-575, 2011.

[4] V. G. Valcour, "Evaluating cognitive impairment in the clinical setting: practical screening and Assessment tools," Topics in Antiviral Medicine, vol. 19, no. 5, pp. 175-180, 2011.

[5] W. R. Tyor, S. L. Wesselingh, J. W. Griffin, J. C. McArthur, and D. E. Griffin, "Unifying hypothesis for the pathogenesis of 
HIV-associated dementia complex, vacuolar myelopathy, and sensory neuropathy," Journal of Acquired Immune Deficiency Syndromes, vol. 9, no. 4, pp. 379-388, 1995.

[6] B. A. Navia, B. D. Jordan, and R. W. Price, "The AIDS dementia complex: I. Clinical features," Annals of Neurology, vol. 19, no. 6, pp. 517-524, 1986.

[7] A. Diamond, "Executive functions," Annual Review of Psychology, vol. 64, pp. 135-168, 2013.

[8] P. P. Christo, "Cognitive alterations associated with HIV-1 infection and AIDS," Revista da Associação Médica Brasileira, vol. 56, no. 2, pp. 242-247, 2010.

[9] K. A. Hestad, J. A. Menon, K. A. Hestad et al., "Sex differences in neuropsychological performance as an effect of human immunodeficiency virus infection: a pilot study in Zambia, Africa," The Journal of Nervous and Mental Disease, vol. 200, no. 4, pp. 336-342, 2012.

[10] E. Vázquez-Justo and M. Rodríguez-Álvarez, "Influence of factors not related with HIV infection on neuropsychological performance of HIV-seropositive patients," Revista de Neurologia, vol. 35, no. 5, pp. 474-480, 2002.

[11] A. L. Busse, W. J. Filho, R. M. Magaldi, V. Coelho, A. C. Melo, and R. A. Betoni, "Effects of resistance training exercise on cognitive performance in elderly individuals with memory impairment: results of a controlled trial," Einstein Journal, vol. 6, no. 4, pp. 402-407, 2008.

[12] R. C. Cassilhas, V. A. Viana, V. Grassmann et al., "The impact of resistance exercise on the cognitive function of the elderly," Medicine and Science in Sports and Exercise, vol. 39, no. 8, pp. 1401-1407, 2007.

[13] A. A. M. Lima, M. P. Kvalsund, P. P. E. de Souza et al., "Zinc, vitamin $A$, and glutamine supplementation in Brazilian shantytown children at risk for diarrhea results in sex-specific improvements in verbal learning," Clinics, vol. 68, no. 3, pp. 351358, 2013.

[14] O. Rest, N. L. van der Zwaluw, M. Tieland et al., "Effect of resistance-type exercise training with or without protein supplementation on cognitive functioning in frail and pre-frail elderly: secondary analysis of a randomized, double-blind, placebocontrolled trial," Mechanisms of Ageing and Development, vol. 136, pp. 85-93, 2014.

[15] H. K. Antunes, R. F. Santos, R. Cassilhas, R. V. Santos, O. F. Bueno, and M. T. Mello, "Exercício físico e função cognitiva: uma revisão," Revista Brasileira de Medicina do Esporte, vol. 12, no. 2, pp. 108-114, 2006.

[16] W. J. R. Bossers, L. H. V. Van Der Woude, F. Boersma, T. Hortobágyi, E. J. A. Scherder, and M. J. G. Van Heuvelen, "A 9week aerobic and strength training program improves cognitive and motor function in patients with dementia: a randomized, controlled trial," The American Journal of Geriatric Psychiatry, vol. 23, no. 11, pp. 1106-1116, 2015.

[17] J. C. Davis, S. Bryan, C. A. Marra, G.-Y. R. Hsiung, and T. LiuAmbrose, "Challenges with cost-utility analyses of behavioural interventions among older adults at risk for dementia," British Journal of Sports Medicine, vol. 49, no. 20, pp. 1343-1347, 2015.

[18] N. R. Graff-Radford, "Can aerobic exercise protect against dementia?" Alzheimer's Research and Therapy, vol. 3, no. 1, article 6, 2011.

[19] T. Liu-Ambrose, L. S. Nagamatsu, P. Graf, B. L. Beattie, M. C. Ashe, and T. C. Handy, "Resistance training and executive functions: a 12-month randomized controlled trial," JAMA Internal Medicine, vol. 170, no. 2, pp. 170-178, 2010.
[20] Y.-K. Chang and J. L. Etnier, "Effects of an acute bout of localized resistance exercise on cognitive performance in middle-aged adults: a randomized controlled trial study," Psychology of Sport and Exercise, vol. 10, no. 1, pp. 19-24, 2009.

[21] Y.-K. Chang, P.-W. Ku, P. D. Tomporowski, F.-T. Chen, and C.-C. Huang, "Effects of acute resistance exercise on late-middle-age adults' goal planning," Medicine \& Science in Sports \& Exercise, vol. 44, no. 9, pp. 1773-1779, 2012.

[22] Y.-K. Chang, C.-L. Tsai, C.-C. Huang, C.-C. Wang, and I.$\mathrm{H}$. Chu, "Effects of acute resistance exercise on cognition in late middle-aged adults: general or specific cognitive improvement?" Journal of Science and Medicine in Sport, vol. 17, no. 1, pp. 51-55, 2014.

[23] P. L. Fazeli, S. P. Woods, R. K. Heaton et al., "An active lifestyle is associated with better neurocognitive functioning in adults living with HIV infection," Journal of NeuroVirology, vol. 20, no. 3, pp. 233-242, 2014.

[24] M. Ortega, L. M. Baker, F. Vaida, R. Paul, B. Basco, and B. M. Ances, "Physical activity affects brain integrity in HIV+ individuals," Neuropsychological Society, vol. 21, no. 10, pp. 880889, 2015.

[25] C. A. Dufour, M. J. Marquine, P. L. Fazeli et al., "Physical exercise is associated with less neurocognitive impairment among HIVinfected adults," Journal of Neuro Virology, vol. 19, no. 5, pp. 410417, 2013.

[26] A. McDermott, L. Zaporojan, P. McNamara et al., "The effects of a 16-week aerobic exercise programme on cognitive function in people living with HIV," AIDS care, vol. 29, no. 6, pp. 667-674, 2017.

[27] P. Newsholme, M. M. R. Lima, J. Procopio et al., "Glutamine and glutamate as vital metabolites," Brazilian Journal of Medical and Biological Research, vol. 36, no. 2, pp. 153-163, 2003.

[28] J. W. Deitmer, A. Bröer, and S. Bröer, "Glutamine efflux from astrocytes is mediated by multiple pathways," Journal of Neurochemistry, vol. 87, no. 1, pp. 127-135, 2003.

[29] M. D. Borges-Santos, F. Moreto, P. C. M. Pereira, Y. Ming$\mathrm{Yu}$, and R. C. Burini, "Plasma glutathione of HIV+ patients responded positively and differently to dietary supplementation with cysteine or glutamine," Nutrition Journal , vol. 28, no. 7-8, pp. 753-756, 2012.

[30] J. R. Leones, M. D. Brito, and C. Caporossi, "A Influencia da Glutamina como Imunofarmaconutriente para Controle de Alteracoes Metabolicas em Pacientes com HIV/AIDS," COORTERevista Científica do Hospital Santa Rosa, no. 3, pp. 37-44, 2016.

[31] R. A. Murden, T. D. McRae, S. Kaner, and M. E. Bucknam, "Mini-mental state exam scores vary with education in black and whites," Journal of the American Geriatrics Society, vol. 39, no. 2, pp. 149-155, 1991.

[32] R. A. Rodrigues, R. L. Oliveira, B. Grinsztejn, and M. T. T. Silva, "Validity of the International HIV Dementia Scale in Brazil," Arquivos de Neuro-Psiquiatria, vol. 71, no. 6, pp. 376-379, 2013.

[33] O. Spreen and E. Strauss, "A compendium of neuropsychological tests," in Administration, Norms, and Commentary, Oxford University Press, New York, NY, USA, 1998.

[34] T. De Nardi, B. Sanvicente-Vieira, M. Prando, L. M. Stein, R. P. Fonseca, and R. Grassi-Oliveira, "Auditory N-back task: different age groups performance," Psicologia: Reflexao e Critica, vol. 26, no. 1, pp. 151-159, 2013.

[35] J. M. Grace, S. J. Semple, and S. Combrink, ““Exercise therapy for human immunodeficiency virus/AIDS patients: guidelines for clinical exercise therapists," Journal of Exercise Science and Fitness, vol. 13, no. 1, pp. 49-56, 2015. 
[36] D. G. Dillon and D. A. Pizzagalli, "Inhibition of action, thought, and emotion: a selective neurobiological review," Applied and Preventive Psychology, vol. 12, no. 3, pp. 99-114, 2007.

[37] R. A. V. Browne, E. C. Costa, M. M. Sales, A. I. Fonteles, J. F. V. N. D. Moraes, and J. D. F. Barros, "Acute effect of vigorous aerobic exercise on the inhibitory control in adolescents," Revista Paulista de Pediatria, vol. 34, no. 2, pp. 154-161, 2016.

[38] M. R. Calomeni, V. F. Silva, L. H. B. Ribeiro, J. Cavalcante, and M. A. F. Siza, "Exercicio fisico e plasticidade neurogenica: benefícios relacionados as funcoes mentais do idoso," Biologicas and Saude, vol. 2, no. 6, 2012.

[39] A.-G. Chen, J. Yan, H.-C. Yin, C.-Y. Pan, and Y.-K. Chang, "Effects of acute aerobic exercise on multiple aspects of executive function in preadolescent children," Psychology of Sport and Exercise, vol. 15, no. 6, pp. 627-636, 2014.

[40] B. Nanda, J. Balde, and S. Manjunatha, "The acute effects of a single bout of moderate-intensity aerobic exercise on cognitive functions in healthy adult males," Journal of Clinical and Diagnostic Research, vol. 7, no. 9, pp. 1883-1885, 2013.

[41] X. Xu, B. A. Jerskey, D. M. Cote et al., "Cerebrovascular perfusion among older adults is moderated by strength training and gender," Neuroscience Letters, vol. 560, pp. 26-30, 2014.

[42] A. F. Kramer, S. J. Colcombe, E. McAuley, P. E. Scalf, and K. I. Erickson, "Fitness, aging and neurocognitive function," Neurobiology of Aging, vol. 26, no. 1, pp. 124-127, 2005.

[43] T. Paillard, "Preventive effects of regular physical exercise against cognitive decline and the risk of dementia with age advancement," Sports Medicine, vol. 1, no. 1, article 20, 2015.

[44] J. Albrecht, M. Sidoryk-Wȩgrzynowicz, M. Zielińska, and M. Aschner, "Roles of glutamine in neurotransmission," Neuron Glia Biology, vol. 6, no. 4, pp. 263-276, 2010.

[45] H. K. Strüder and H. Weicker, "Physiology and pathophysiology of the serotonergic system and its implications on mental and physical performance. Part II," International Journal of Sports Medicine, vol. 22, no. 7, pp. 482-497, 2001.

[46] S. Ando, M. Kokubu, Y. Yamada, and M. Kimura, "Does cerebral oxygenation affect cognitive function during exercise?" European Journal of Applied Physiology, vol. 111, no. 9, pp. 19731982, 2011.

[47] M. Berk, F. Ng, O. Dean, S. Dodd, and A. I. Bush, "Glutathione: a novel treatment target in psychiatry," Trends in Pharmacological Sciences, vol. 29, no. 7, pp. 346-351, 2008.

[48] R. J. Ellis, J. Joseph, and S. M. de Almeida, "NeuroAIDS in Brazil," Journal of Neuro Virology, vol. 13, no. 2, pp. 89-96, 2007.

[49] E. Mormont and P. Laloux, "Strategie therapeutique dans le traitement initial de la maladie de Parkinson," Louvion Medical, vol. 121, no. 4, pp. 93-99, 2002.

[50] N. Ballatori, S. M. Krance, S. Notenboom, S. Shi, K. Tieu, and C. L. Hammond, "Glutathione dysregulation and the etiology and progression of human diseases," Biological Chemistry, vol. 390, no. 3, pp. 191-214, 2009.

[51] I. Suarez, G. Bodega, and B. Fernandez, "Glutamine synthetase in brain: effect of ammonia," Neurochemistry International, vol. 41, no. 2-3, pp. 123-142, 2002.

[52] G. J. Pruna, J. R. Hoffman, W. P. McCormack et al., "Effect of acute L-Alanyl-L-Glutamine and electrolyte ingestion on cognitive function and reaction time following endurance exercise," European Journal of Sport Science, vol. 16, no. 1, pp. 72-79, 2016.

[53] T. W. McAllister, M. B. Sparling, L. A. Flashman, and A. J. Saykin, "Neuroimaging findings in mild traumatic brain injury," Journal of Clinical and Experimental Neuropsychology, vol. 23, no. 6, pp. 775-791, 2001.
[54] A. D. Baddeley, "Working memory: looking back and looking forward," Nature Reviews Neuroscience, vol. 4, no. 10, pp. 829839, 2003. 


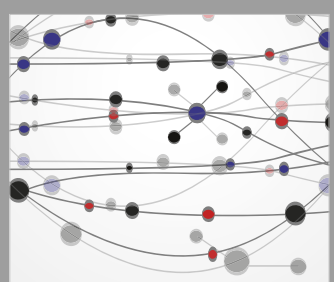

The Scientific World Journal
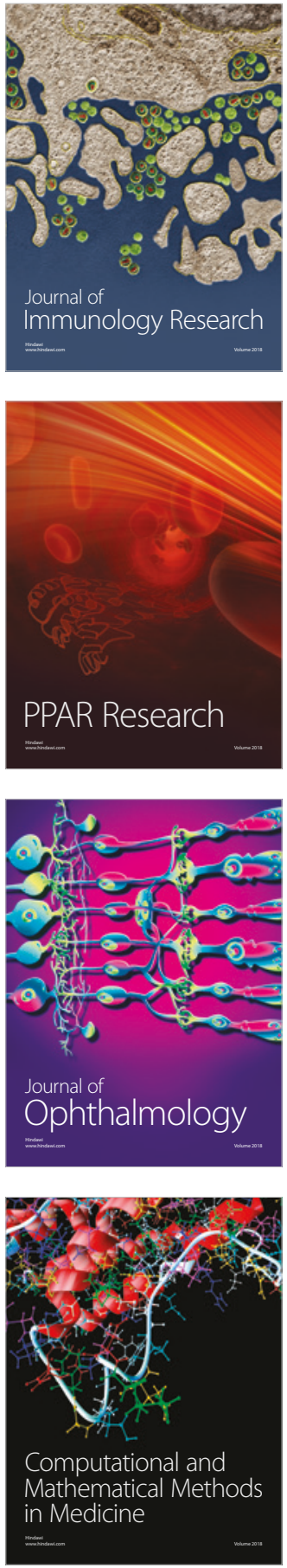

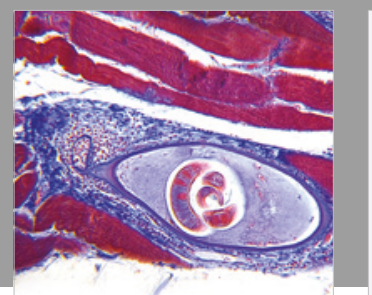

Gastroenterology Research and Practice

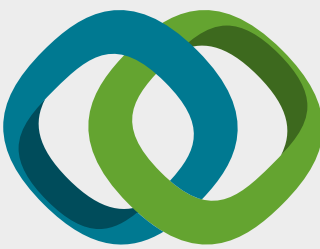

\section{Hindawi}

Submit your manuscripts at

www.hindawi.com
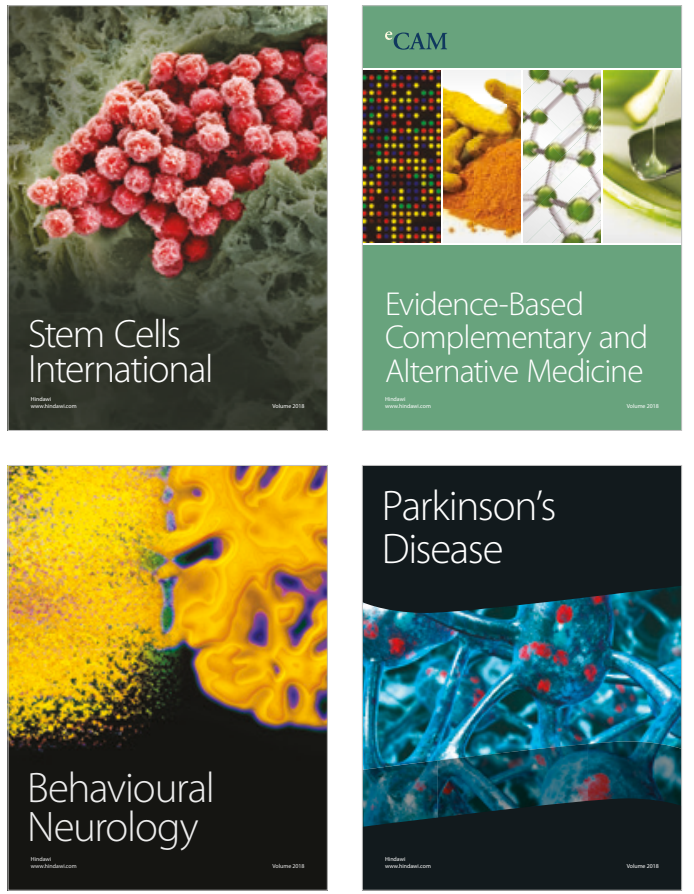

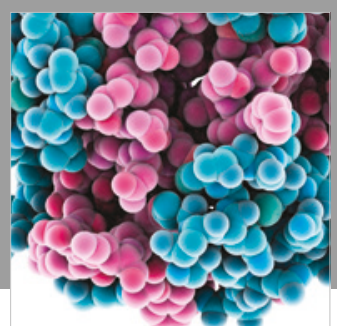

ournal of

Diabetes Research

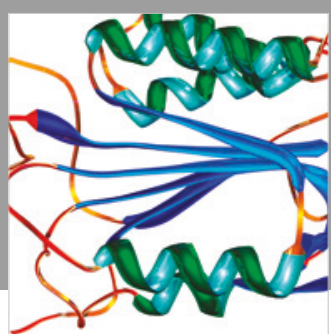

Disease Markers
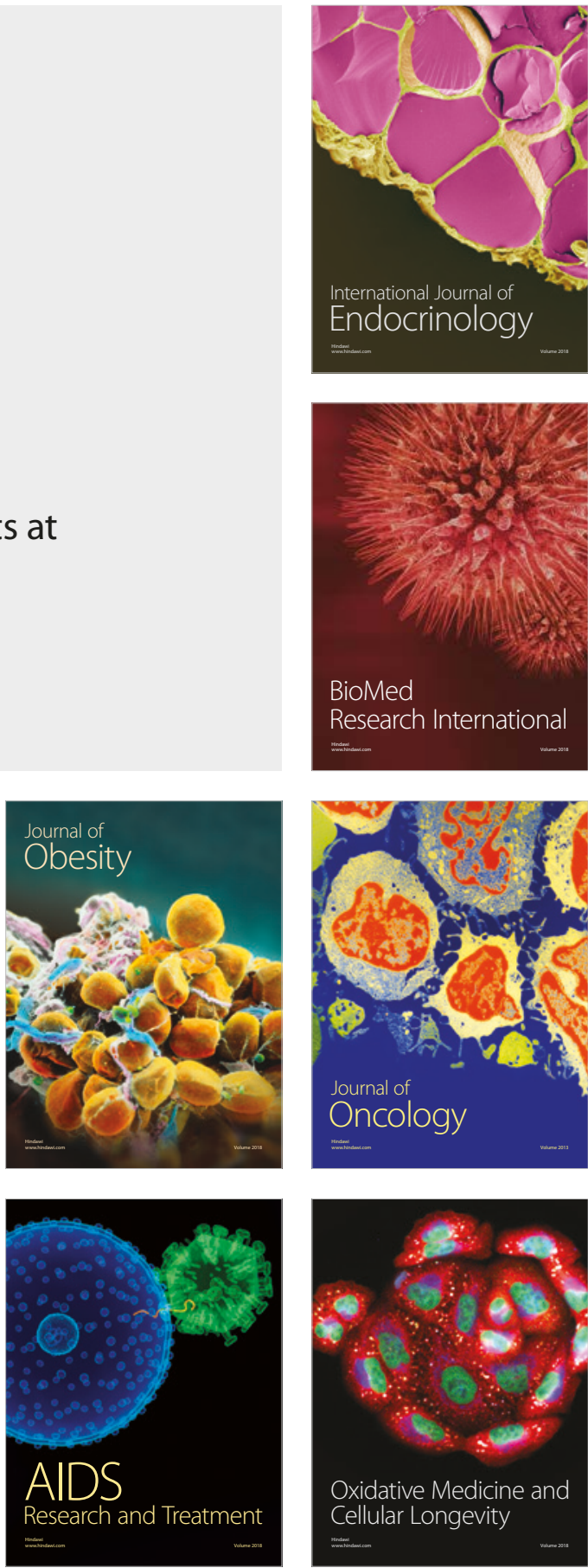